\title{
Treatment adherence among patients with hypertension: findings from a cross- sectional study
}

\author{
Fahad M. Algabbani ${ }^{* *}$ and Aljoharah M. Algabbani
}

\begin{abstract}
Background: Hypertension is a major risk factor for cardiovascular disease, which is the leading cause of mortality globally. Patient's adherence to treatment is a cornerstone factor in controlling hypertension and its complications. This study assesses hypertension patients' adherence to treatment and its associated factors.

Methods: This cross-sectional study conducted in Riyadh, Saudi Arabia. The study targeted outpatients aged $\geq 18$ years who were diagnosed with hypertension. Participants were recruited using a systemic sampling technique. The two main measurements were assessing adherence rate of antihypertensive medications using Morisky scale and identifying predictors of poor medication adherence among hypertensive patients including socio-economic and demographic data, health status, clinic visits, medication side effects, medications availability, and knowledge. Descriptive and logistic regression analyses were performed to assess factors associated with poor adherence.

Results: A total of 306 hypertensive outpatients participated in this study. $42.2 \%$ of participants were adherent to antihypertensive medications. Almost half of participants (49\%) who reported having no comorbidities were adherent to antihypertensive medications compared to participants with one or more than one comorbidities 41 , $39 \%$ respectively. The presence of comorbid conditions and being on multiple medications were significantly associated with medication adherence $(P$-values, respectively, $<0.004,<0.009)$. Patients with good knowledge about the disease and its complications were seven times more likely to have good adherence to medication $(P<0.001)$.
\end{abstract}

Conclusions: Non-adherence to medications is prevalent among a proportion of hypertensive patients which urges continuous monitoring to medication adherence with special attention to at risks groups of patients. Patients with comorbidities and on multiple medications were at high risk of medication non-adherence. Patients' knowledge on the disease was one of the main associated factors with non-adherence.

Keywords: High blood pressure, Uncontrolled hypertension, Nonadherence

\footnotetext{
*Correspondence: fahad.gabbani@gmail.com

${ }^{1}$ Family Medicine Department, Prince Sultan Military Medical City (PSMMC),

Riyadh, Riyadh, Saudi Arabia

Full list of author information is available at the end of the article
}

(C) The Author(s). 2020 Open Access This article is licensed under a Creative Commons Attribution 4.0 International License, which permits use, sharing, adaptation, distribution and reproduction in any medium or format, as long as you give appropriate credit to the original author(s) and the source, provide a link to the Creative Commons licence, and indicate if changes were made. The images or other third party material in this article are included in the article's Creative Commons licence, unless indicated otherwise in a credit line to the material. If material is not included in the article's Creative Commons licence and your intended use is not permitted by statutory regulation or exceeds the permitted use, you will need to obtain permission directly from the copyright holder. To view a copy of this licence, visit http://creativecommons.org/licenses/by/4.0/ The Creative Commons Public Domain Dedication waiver (http://creativecommons.org/publicdomain/zero/1.0/) applies to the data made available in this article, unless otherwise stated in a credit line to the data. 


\section{Background}

Hypertension is one of the most common chronic diseases in Saudi Arabia and a rising health burden, affecting $26.1 \%$ adult population [1]. Hypertension is a major risk factor for heart failure, myocardial infarction, cerebrovascular disease, and renal failure [2]. Controlling hypertension reduces the risk of cerebrovascular accident (CVA), coronary heart disease, congestive heart failure, and mortality [2, 3]. There are several factors that affect blood pressure control. Patients' adherence to treatment is one of the major factors in controlling blood pressure and preventing hypertension complications [3]. The World Health Organization (WHO) defines adherence to long-term therapy as "the extent to which a person's behavior-taking medication, following a diet, and/or executing lifestyle changes-corresponds with agreed recommendations from a healthcare provider" [3]. Patients with a high level of medication adherence were found to have better blood pressure control [4]. Still, adherence to hypertension treatment is challenging, due to the asymptomatic nature of the disease [5].

Several studies investigated the adherence rate among hypertension patients and sociodemographic factors affecting medication adherence including age, gender, comorbidities, patients' knowledge about the disease, the number of medications. A study conducted in Saudi Arabia showed that only $34.7 \%$ of male hypertensive patients were found to be adherent to their medication [6]. The study reported a negative association between the presence of comorbidities and the adherence level [6]. A cross-sectional study on medication adherence among patients with hypertension in Malaysia, found an association between adherence and good knowledge of the medications and disease [7]. The study also found that the increase in the number of drugs patients taking has a negative effect on medication adherence [7]. Other studies had similar findings regarding the association between the number of medications and adherence [8-10]. In a cross-sectional study conducted in Iran, older patients reported high adherence to antihypertensive medication and better knowledge of their disease than younger patients [9]. However, number of studies reported no significant associations between age and medication adherence $[8,11]$. Female patients were more likely to adhere to their medication, compared to males [12]. Another study on the prevalence and predictors of poor antihypertensive reported that male patients were more adherent than female patients [13]. Some studies reported no relationship between gender and adherence [9, 11].

Educational level and health literacy were shown to be associated with medication adherence. A cross-sectional study conducted in Iraq showed that adherence decreased in patients with primary and secondary school education, while no significant difference among patients with higher education and undereducated patients [14]. Similar results found in a systematic review conducted in hypertension management and medication adherence [15]. On the other hand, no association between educational level and adherence was found in a study conducted in Saudi Arabia [8]. However, good health knowledge of hypertension shown to be associated with good adherence to medication treatment in several studies [7, 11]. Two cross-sectional studies conducted in Turkey and Algeria showed a significant association between knowledge of complications related to hypertension and good adherence to antihypertensive therapy [16, 17].

Hypertension is one of the major health issues in Saudi Arabia; affecting more than a quarter of the Saudi adult population [1]. Only $37 \%$ of hypertensive patients on medication have their blood pressure controlled [18]. Non-adherence to antihypertensive medications is a potential contributing factor to uncontrolled hypertension. With limited studies conducted to investigate this challenging issue, this cross-sectional study aims to assess the adherence rate among hypertensive patients and associated factors affecting adherence to antihypertensive medications.

\section{Methods}

\section{Study design and sampling}

This cross-sectional study was conducted to determine the adherence rate of antihypertensive medications and the predictors of poor medication adherence among hypertensive patients at primary health clinics (PHCs) in Prince Sultan Medical City (PSMMC) in Riyadh the capital city of Saudi Arabia. Single population proportion formula was used to calculate the sample size based on the prevalence of hypertension in Saudi Arabia (26.1\%) [1]. With a 95\% confidence level and a 5\% margin of error, a total of 306 randomly selected outpatients with hypertension following up at primary health clinics were included in this study.

\section{Participants recruitment}

Participants in this study were recruited using a systemic sampling technique. Every fourth consecutive patient who fits the criteria was included. Arabic speaker patients older than 18 years who have been diagnosed with hypertension for more than three months were included in this study. Patients who do not speak Arabic had mental retardation, secondary hypertension, or who were younger than 18 years old were excluded from the study. The data was collected using a self-administered questionnaire that was distributed in the waiting area of the pharmacy. Illiterate participants were interviewed by a trained data collector. Before participants' recruitment in 
the study, informed consent was obtained from all patients after a full explanation of the study. The study was approved and supervised by the institution review board (IRB) of Prince Sultan Medical City.

\section{Measurements}

The questionnaire consists of four main sections. The first section assesses participants' socio-economic factors including age, gender, marital status, occupation, the highest level of education currently attained, occupation, and monthly income. The second section assesses the factors affecting medication adherence including comorbidities, number of medications, number of daily doses, number of clinic visits, the distance to the clinic, medication side effects, medication availability at the pharmacy. The third section aimed to assess patients' adherence to treatment. The fourth part assesses the patients' knowledge about hypertension.

Medication adherence was assessed using the 8- items Morisky scale [19]. Morisky scale has been validated and found to be reliable $(\alpha=.83)$ [20]. The scale is based on the patients' self-response and consists of eight questions, seven items with yes or no response, and one item with a 5-point Likert scale response option. The total score ranges from 1 to 8 , the patient whose adherence score was six or more is considered adherent. For linguistic validation, questions were translated forward and backward into Arabic by an independent translator.

The participant's knowledge about hypertension was assessed using nine structured questions. The questions focused on different aspects of hypertension, namely blood pressure target, lifestyle modification effect, complications, treatment, and cure. During analysis, patients who answered $<70 \%$ were considered to have low knowledge and patient how answered $\geq 70 \%$ of the questions were considered to have good knowledge. The $70 \%$ cutoff is based on the minimally acceptable level of quality control at PSMMC [21].

The questionnaire was pre-tested and then a pilot survey was conducted on 20 patients for clarity and feasibility. The questionnaire was also evaluated and reviewed by two independent family medicine consultants at Prince Sultan Medical City for validation.

\section{Data analysis}

Frequencies and percentages were used to assess participants' characteristics. Chi-square analysis was used to determine the association between demographic, socioeconomic, and clinical factors with medication adherence. Logistic regression analysis was performed to assess factors associated with poor adherence. The variables were analyzed collectively using logistic regression to study the potential factors to avoid confounding bias. The association was considered statistically significant if the $P$-value was less than 0.05 . Statistical Package for Social Sciences version 25 and Statistical Analysis System version 9.4 was used for data analysis.

\section{Results}

A total of 306 outpatients who have hypertension participated in this study. Approximately $43 \%$ of the participants' ages range was between 56 and 65 . The majority of participants were married (92\%), employed (61\%), and had a high school diploma or above (80\%). Most of the participants were middle income in the 5000-10,000 Saudi Riyal range of monthly income. Nearly one-third (28.1\%) of the respondents in this study had no comorbidities while two-thirds reported having one or more comorbidities. The demographic, and socioeconomic clinical characteristics of the participants are presented in Table 1.

Only $13 \%$ of the respondents live at a distance of less than half an hour from the clinic. Of the total participants, $14.1 \%$ reported visiting the primary health clinic once in the last year, $29.4 \%$ twice, $24.2 \%$ three times. The majority of participants reported taking less than four medications a day and $31.4 \%$ reported taking four or more medications a day. As to antihypertensive medication side effects, $19.6 \%$ reported having medication side effects. Only $4.9 \%$ of the participants reported that they stop taking their antihypertensive medications when they get sick. Approximately $9 \%$ of the participants reported that they stop taking their medications when it is not available at the pharmacy. Findings show that half (50.7\%) of the participants were knowledgeable about the disease. The clinical characteristics of the participants are presented in Table 1.

Figure 1 presents the percentage of participants' adherence to antihypertensive treatment. Based on Morisky scale test results, $42.2 \%$ of the participants in this study were adherent to antihypertensive medications, while $57.8 \%$ were not adherent.

Table 2 presents the adherence rate in relation to the participants' demographic, socioeconomic, and clinical characteristics. The presence of comorbid conditions is significantly associated with medication adherence $(P<0.001)$. Almost half of participants $(49 \%)$ who reported having no comorbidities were adherent to antihypertensive medications compared to the participants with one or more than one comorbidities $41,39 \%$ respectively. As for the number of medications, the adherence rate was found to be better among patients who were taking less than four medications (47.1\%) compared to patients who were taking four or more medications (31.3\%). Patients who visited the clinic once in the last year were more adherent than those who visited the clinic more than once $(p<0.05)$. No significant association between age, gender, 
Table 1 Demographic, socioeconomic and clinical characteristics of patients

\begin{tabular}{|c|c|c|c|}
\hline Variables & Categories & Frequency & Percentage \\
\hline \multirow[t]{4}{*}{ Age } & Less than 45 & 39 & 12.7 \\
\hline & $45-55$ & 96 & 31.4 \\
\hline & $56-65$ & 132 & 43.1 \\
\hline & $\begin{array}{l}\text { More than } \\
65\end{array}$ & 39 & 12.7 \\
\hline \multirow[t]{2}{*}{ Gender } & Male & 227 & 74.2 \\
\hline & Female & 79 & 25.8 \\
\hline \multirow[t]{4}{*}{ Marital status } & Married & 282 & 92.2 \\
\hline & Single & 5 & 1.6 \\
\hline & Divorced & 11 & 3.6 \\
\hline & $\begin{array}{l}\text { Widow/ } \\
\text { Widower }\end{array}$ & 8 & 2.6 \\
\hline \multirow[t]{5}{*}{ Educational level } & College & 76 & 24.8 \\
\hline & High school & 170 & 55.6 \\
\hline & $\begin{array}{l}\text { Middle } \\
\text { school }\end{array}$ & 14 & 4.6 \\
\hline & $\begin{array}{l}\text { Elementary } \\
\text { school }\end{array}$ & 40 & 13.1 \\
\hline & Illiterate & 6 & 2 \\
\hline \multirow[t]{5}{*}{ Occupation } & Public & 89 & 29.1 \\
\hline & Military & 90 & 29.4 \\
\hline & Private & 8 & 2.6 \\
\hline & Retired & 75 & 24.5 \\
\hline & Unemployed & 44 & 14.4 \\
\hline \multirow[t]{5}{*}{ Monthly income in Saudi Riyal } & $\begin{array}{l}\text { Less than } \\
5000\end{array}$ & 82 & 26.8 \\
\hline & 5000-9999 & 149 & 48.7 \\
\hline & $\begin{array}{l}10,000-14 \\
999\end{array}$ & 47 & 15.4 \\
\hline & $\begin{array}{l}15,000-20 \\
000\end{array}$ & 21 & 6.9 \\
\hline & $\begin{array}{l}\text { More than } \\
20,000\end{array}$ & 7 & 2.3 \\
\hline \multirow[t]{3}{*}{ Comorbidity } & No & 86 & 28.1 \\
\hline & One & 109 & 35.6 \\
\hline & $\begin{array}{l}\text { More than } \\
\text { one }\end{array}$ & 111 & 36.3 \\
\hline \multirow{5}{*}{$\begin{array}{l}\text { Number of clinic visits in the last } \\
\text { year }\end{array}$} & One & 43 & 14.1 \\
\hline & Two & 90 & 29.4 \\
\hline & Three & 74 & 24.2 \\
\hline & Four & 66 & 21.6 \\
\hline & $\begin{array}{l}\text { More than } \\
\text { four }\end{array}$ & 33 & 10.8 \\
\hline \multirow[t]{3}{*}{$\begin{array}{l}\text { Distance (driving time) from } \\
\text { home to clinic }\end{array}$} & $\begin{array}{l}\text { Less than } \\
30 \text { min }\end{array}$ & 40 & 13.1 \\
\hline & $30-60 \mathrm{~min}$ & 209 & 68.3 \\
\hline & $\begin{array}{l}\text { More than } \\
60 \text { min }\end{array}$ & 57 & 18.6 \\
\hline
\end{tabular}

Table 1 Demographic, socioeconomic and clinical characteristics of patients (Continued)

\begin{tabular}{llll}
\hline Variables & Categories & Frequency & Percentage \\
\hline Number of medication & Less than 4 & 210 & 68.6 \\
& 4 or more & 96 & 31.4 \\
Presence of side effects & Yes & 60 & 19.6 \\
& No & 246 & 80.4 \\
Stop taking medication when & Yes & 15 & 4.9 \\
he/she is sick & No & 291 & 95.1 \\
Stop taking medications when it & Yes & 27 & 8.8 \\
is not available at the pharmacy & No & 279 & 91.2 \\
Knowledge about hypertension & Good & 155 & 50.7 \\
& Poor & 151 & 49.3 \\
\hline
\end{tabular}

income, educational level, and distance from home to the clinic.

The participants were asked eight questions about hypertension. Table 3 shows the distribution of the correct and incorrect answers giving by the participants. Most participants (64.4\%) knew the target blood pressure for hypertensive patients and $40.8 \%$ think that hypertension can be cured. The majority (78\%) knew that a low salt diet helps in lowering high blood pressure. Only $61 \%$ knew that hypertension can affect eyes and $13.4 \%$ reported that they stop taking their medication when they feel their blood pressure under control.

Adherence to antihypertensive medications among patients with good and poor knowledge levels about hypertension was assessed based on nine structured questions. Figure 2 shows the adherence to hypertension treatment among patients with good and poor knowledge level. $57.4 \%$ of patients with good knowledge levels were adherent compared to $42.6 \%$ who were not adherent. The majority $(73.5 \%)$ of patients with poor knowledge levels were not adherent to treatment.

Table 4 presents the factors associated with good adherence. When conducting binary logistic regression, knowledge about the disease was found to be significantly associated with adherence. Patients with good knowledge about the disease were seven times more likely to have good adherence to antihypertensive medications than those with poor knowledge (AOR 7.4 [95\% CI: 4.177-13.121], $p<0.001)$.

\section{Discussion}

Several studies have investigated factors affecting medication adherence. This study shows that the level of adherence to antihypertensive medications is low. In this sample the adherence rate to hypertension treatment was found to be only $42 \%$, which is similar to the study conducted in Al-Khobar and higher than the study conducted in Taif where adherence rate was found to be 47 


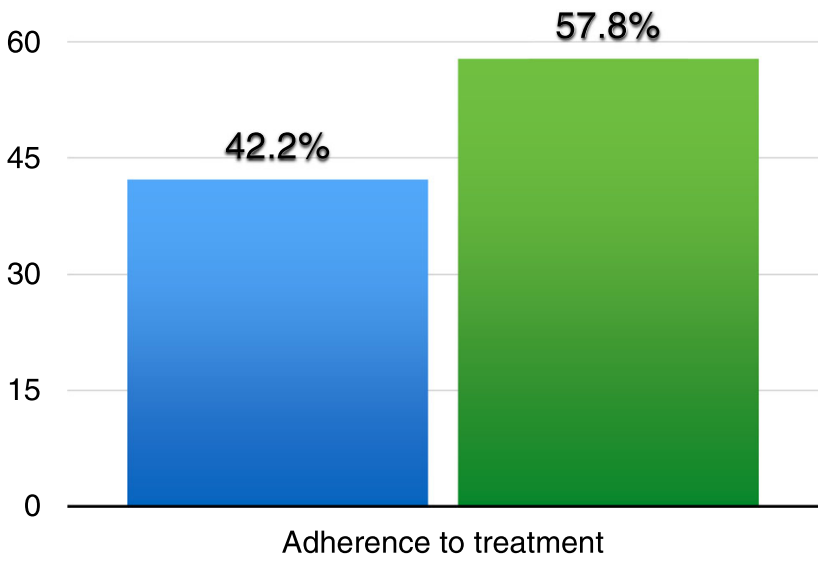

*The medication adherence status was determined based on Morisky scale.

Fig. 1 Distribution of patients according to their medication adherence status*

and $34.7 \%$, respectively $[6,8]$. Other studies conducted in different countries reported adherence rates ranging from 15 to $88 \%$ [22-25]. This discrepancy in adherence rate is potentially due to the differences in population characteristics, medication adherence assessment tools, and healthcare systems.

The association between sociodemographic and socioeconomic factors and adherence level has been investigated in several studies. In a study done in Hong Kong, older patients were found to be more adherent. However, in this study, there was no association between age and adherence. In another study done in the United States, female patients were less adherent to hypertension medication compared to male patients [13]. A study conducted in Malaysia reported that female patients were more adherent than male patients [22]. Our study showed that there was no significant relationship between gender and adherence. A meta-analysis suggested that the association between age, gender, and adherence level is weak [26]. The results of our study also demonstrate no significant relationship between marital status and educational level with adherence, which is similar to findings reported by other studies $[9,27]$.

Previous research found that shorter traveling time from residence to the healthcare facility could increase patients' adherence [28]. A study in Ethiopia found that the adherence level was lower in patients who lived more than 10 $\mathrm{km}$ from healthcare facilities [29]. A cross-sectional observational study done in Northwest Ethiopia indicated that patients who live less than $10 \mathrm{~km}$ from the healthcare facility had an adherence rate of $74 \%$ compared to $58 \%$ for patients who live far from the healthcare facility [29]. As the authors attributed this problem to poor infrastructure and lack of transportation in Ethiopia, the study suggested that shorter traveling time from residence to the healthcare facility could increase patients' adherence [29]. In this study, distance from home to the clinic was not associated with hypertensive treatment. These differences may be due to the higher level of car ownership in Saudis Arabia which makes it easier to access health care facilities [30].

Only $8.8 \%$ of the participants reported not taking their medication when it is not available at the hospital pharmacy. This low percentage may be explained by the multiple community health centers in Saudi Arabia which provide free health care including medications dispensing. Moreover, the medication cost at private pharmacies in Saudi Arabia is affordable for most patients. According to the published Saudi Hypertension Management Guidelines the prices of the antihypertensive medications ranges between 7 to 118 Saudi Riyal (about 2 to 31 US Dollar) [31].

Many patients with hypertension will need two or more antihypertensive medications to achieve goal blood pressure [2]. In this sample significant association was observed between the number of medications and adherence level. The adherence rate among patients taking less than four medications was $47.1 \%$ compared to $31.3 \%$ to those who take four or more medications. Similarly, other studies reported the negative association between the number of medication and adherence levels [29, 32]. 
Table 2 Sociodemographic, economic, and clinical characteristics of patients according to their medication adherence status

\begin{tabular}{|c|c|c|c|c|}
\hline Variables & Categories & N Adherent (\%) & N non-adherent (\%) & $P$-value \\
\hline \multirow[t]{4}{*}{ Age } & $<45$ & $15(38.5 \%)$ & $24(61.5 \%)$ & \multirow[t]{4}{*}{0.706} \\
\hline & $46-55$ & $45(46.9 \%)$ & $51(53.1 \%)$ & \\
\hline & $54-65$ & $54(40.9 \%)$ & $78(59.1 \%)$ & \\
\hline & $>65$ & $15(38.5 \%)$ & $24(61.5 \%)$ & \\
\hline \multirow[t]{2}{*}{ Gender } & Male & $99(43.6 \%)$ & $128(56.4 \%)$ & \multirow[t]{2}{*}{0.382} \\
\hline & Female & $30(38 \%)$ & $49(62 \%)$ & \\
\hline \multirow[t]{4}{*}{ Marital status } & Married & $121(42.9 \%)$ & $161(57.1 \%)$ & \multirow[t]{4}{*}{0.766} \\
\hline & Single & $2(40 \%)$ & $3(60 \%)$ & \\
\hline & Divorced & $3(27.3 \%)$ & $8(72.7 \%)$ & \\
\hline & Widow/Widower & $3(37.5 \%)$ & $5(62.5 \%)$ & \\
\hline \multirow[t]{5}{*}{ Educational level } & Collage & $30(39.5 \%)$ & $46(60,5 \%)$ & \multirow[t]{5}{*}{0.937} \\
\hline & High school & $73(42.9$ & $97(57.1 \%)$ & \\
\hline & Middle school & $7(50 \%)$ & $7(50 \%)$ & \\
\hline & Elementary school & $17(42.5 \%)$ & $23(57.5 \%)$ & \\
\hline & |lliterate & $2(33.3 \%)$ & $4(66 \%)$ & \\
\hline \multirow[t]{5}{*}{ Occupation } & Public & $34(38.2 \%)$ & $55(61.8 \%)$ & \multirow[t]{5}{*}{0.487} \\
\hline & Military & $44(48.9 \%)$ & $46(51.1 \%)$ & \\
\hline & Private & $2(25 \%)$ & $6(75 \%)$ & \\
\hline & Retired & $32(42.7 \%)$ & $43(57.3 \%)$ & \\
\hline & Unemployed & $17(38.6 \%)$ & $27(61.4 \%)$ & \\
\hline \multirow[t]{5}{*}{ Monthly income in Saudi Riyal } & $<5000$ & $38(46.3 \%)$ & $44(53.7 \%)$ & \multirow[t]{5}{*}{0.599} \\
\hline & 5000-9999 & $56(37.6 \%)$ & $93(62.4 \%)$ & \\
\hline & $10,000-14,999$ & $23(48.9 \%)$ & $24(51.1 \%)$ & \\
\hline & $15,000-20,000$ & $9(42.9 \%)$ & $12(57.1 \%)$ & \\
\hline & $>20,000$ & $3(42.9 \%)$ & $4(57.1 \%)$ & \\
\hline \multirow[t]{3}{*}{ Comorbidities } & No comorbidities & $49(57 \%)$ & $47(43 \%)$ & \multirow[t]{3}{*}{0.004} \\
\hline & One & $41(37.6 \%)$ & $68(62 \%)$ & \\
\hline & $>1$ & $39(35.1 \%)$ & $72(64.9 \%)$ & \\
\hline \multirow[t]{2}{*}{ Number of medication } & $<4$ & $99(47.1 \%)$ & $111(52.9 \%)$ & \multirow[t]{2}{*}{0.009} \\
\hline & $\geq 4$ & $30(31.3 \%)$ & $66(68.8 \%)$ & \\
\hline \multirow[t]{2}{*}{ Presence of side effects } & Yes & $19(31.7 \%)$ & $41(68.3 \%)$ & \multirow[t]{2}{*}{0.066} \\
\hline & No & $110(44.7 \%)$ & $136(55.3 \%)$ & \\
\hline \multirow[t]{2}{*}{ Stop taking medications when he/she's sick } & Yes & $3(20 \%)$ & $12(80 \%)$ & \multirow[t]{2}{*}{0.75} \\
\hline & No & $126(43.3 \%)$ & $165(56.7 \%)$ & \\
\hline \multirow{2}{*}{$\begin{array}{l}\text { Stop taking medications when it is not } \\
\text { available at the pharmacy }\end{array}$} & Yes & $7(25.9 \%)$ & $20(74.1 \%)$ & \multirow[t]{2}{*}{0.074} \\
\hline & No & $122(43.7 \%)$ & $157(56.3 \%)$ & \\
\hline \multirow[t]{3}{*}{ Distance from home to the clinic } & $<30 \min$ & $16(40 \%)$ & $24(60 \%)$ & 0.276 \\
\hline & $30-60 \mathrm{~min}$ & $94(45 \%)$ & $115(55 \%)$ & \\
\hline & $>60 \mathrm{~min}$ & $19(33.3 \%)$ & $38(66.7 \%)$ & \\
\hline Number of clinic visits in last year & One & $25(58.1 \%)$ & $18(41.9 \%)$ & 0.044 \\
\hline & Two & $42(46.7 \%$ & $48(53.3 \%)$ & \\
\hline & Three & $26(35.1 \%)$ & $48(64.9 \%)$ & \\
\hline & Four & $27(40.9 \%)$ & $39(59.1 \%)$ & \\
\hline & $<4$ & $9(27.3 \%)$ & $24(72.7 \%)$ & \\
\hline Knowledge about hypertension & Good & $89(57.4 \%)$ & $66(42.6 \%)$ & $<0.005$ \\
\hline & Poor & $40(26.5 \%)$ & $111(73.5 \%)$ & \\
\hline
\end{tabular}


Table 3 The patients' responses to hypertension knowledge questions

\begin{tabular}{lll}
\hline Assessment items & N correct (\%) & N Incorrect (\%) \\
\hline $\begin{array}{l}\text { The target blood pressure level } \\
\text { for hypertensive patients }\end{array}$ & $188(64.4 \%)$ & $118(38.6 \%)$ \\
$\begin{array}{l}\text { Can hypertension be cured? } \\
\begin{array}{l}\text { Exercise help in controlling } \\
\text { blood pressure }\end{array}\end{array}$ & $181(59.2 \%)$ & $125(40.8 \%)$ \\
$\begin{array}{l}\text { Reducing salt intake help in } \\
\text { controlling blood pressure }\end{array}$ & $241(78.1 \%)$ & $21(6.9 \%)$ \\
$\begin{array}{l}\text { High blood pressure may } \\
\text { affect the heart? }\end{array}$ & $289(94.4 \%)$ & $17(5.6 \%)$ \\
$\begin{array}{l}\text { High blood pressure may } \\
\text { affect the brain? }\end{array}$ & $273(77.5 \%)$ & $69(22.5 \%)$ \\
$\begin{array}{l}\text { High blood pressure may } \\
\text { affect the kidneys? }\end{array}$ & $265(86.6 \%)$ & $41(13.4 \%)$ \\
$\begin{array}{l}\text { High blood pressure may } \\
\text { affect the eyes? }\end{array}$ & $188(61.4 \%)$ & $118(38.6 \%)$ \\
$\begin{array}{l}\text { Stop taking medications when } \\
\text { you feel like your blood } \\
\text { pressure or your symptoms } \\
\text { are under control? }\end{array}$ & $264(86.3 \%)$ & $42(13.7 \%)$ \\
\hline
\end{tabular}

Findings indicate that patients with multiple comorbidities were less adherent to antihypertensive medication, which is inconsistent with a previous study done in Taif which showed a negative association between the presence of comorbidity and adherence level [6]. This may be related to the fact that most patients with multiple comorbidities require taking multiple complex medications.

The result of our study showed that the patient who visited the clinic once in the last year were more adherent than the patient who visited the clinic more than once. This could be explained by that most patients with multiple comorbidities and on multiple medications frequently visit the clinic for issues related to their disease and to refill prescriptions.

Our study demonstrated the positive association between knowledge and adherence levels. Patients who had good knowledge were more adherent to the treatment [29]. Previous studies showed that patients who know the ideal target blood pressure level were more adherent to their medications $[16,20]$. In this study, only $64.4 \%$ of the participants knew the ideal target of blood pressure and $40.8 \%$ of the patients believe that hypertension can be cured. A study conducted in Rajshahi, Bangladesh found that $65.8 \%$ of the patients believe that hypertension is curable. Patients how have been educated by their physicians and healthcare providers were more adherents to treatment as they have a better understanding of the disease nature, the ideal target of blood pressure, and the complications of hypertension [33]. Therefore, patient education in disease nature and

$$
80
$$

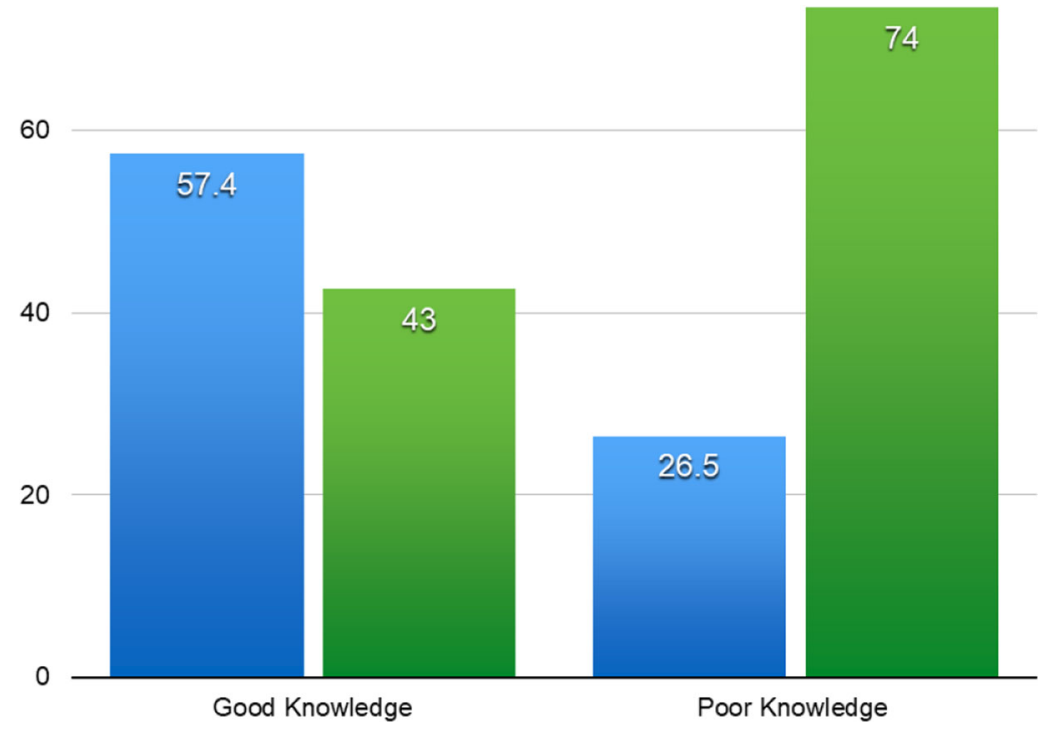

*The knowledge level was based on seventy percent cut-off, the minimally acceptable level of quality control at PSMMC (20)

Fig. 2 Adherence to hypertension treatment among patients with good and poor knowledge level* 
Table 4 Logistic regression results of factors associated with good medication adherence

\begin{tabular}{lllll}
\hline Variables & AOR & P-value & 95\% Confidence interval \\
\hline Age & 1.204 & 0.255 & 0.875 & 1.657 \\
Gender & 1.314 & 0.401 & 0.695 & 2.483 \\
Education & 0.766 & 0.096 & 0.559 & 1.049 \\
Knowledge about hypertension & 7.403 & $<0.001$ & 4.177 & 13.121 \\
Daily dosing & 1.214 & 0.190 & 0.908 & 1.621 \\
\hline
\end{tabular}

management is considered a key factor in the treatment of hypertension.

The study findings were based on self-reported survey. Self-reported data is a common method used in a crosssectional study. However, self-reported data is subjected to biases such as response and recall biases that can lead to under- or overestimation of findings. On the other hand, adherence in this study was measured based on a validated self-report adherence scale and knowledge was tested based on evaluated and reviewed assessment items by two independent family medicine consultants. Moreover, this study conducted in one of the largest medical cities that serves a large community in the capital city Riyadh. Due to the study design and sampling method, study findings cannot be generalized and temporal relationships cannot be established between risk factors and adherence. Nevertheless, this study provides a snapshot of adherence to antihypertensive medication status and associated determinates among outpatients. Future large scale longitudinal studies will contribute to a better understanding of adherence status and associated factors among hypertensive patients.

\section{Conclusions}

Non-adherence to medications is prevalent in proportion of patients with hypertension. Therefore, there is an urge to continually monitor patients' adherence to antihypertensive medication using a standardized scale. Patients with comorbidities and on multiple medications were at higher risk of non-adherence. There is a need to encourage patients on multiple medications to use adherence aids such as weekly pill organizers and medication alarm devices. Hypertensive patients' knowledge of the disease and its complications was one of the main factors affecting patients' adherence to treatment. Implementation of health awareness interventions and education programs intended for hypertensive patients will help improve medication adherence.

\section{Abbreviations}

AOR: Adjusted odd ratio; OR: Odd ratio; Cl: Confidence interval; BP: Blood pressure; P: P value; PSMMC: Prince Sultan Medical City; PHC: primary health clinic; IRB: institution review board; CVA: Cerebrovascular accident; WHO: The World Health Organization

Acknowledgments

Not applicable.
Authors' contributions

The study design was conceptualized by FA and AA. Data collection was managed by FA and data analysis and interpretation were conducted by FA and AA. All authors participated in writing and editing the manuscript. All authors read and approved the final manuscript.

Funding

Not applicable.

Availability of data and materials

The data sets generated during and/or analyzed during the current study are available from the corresponding authors on reasonable request.

Ethics approval and consent to participate

Ethical approval was obtained from institution review board (IRB) of Prince Sultan Medical City. Before participants' recruitment in the study, informed consent was obtained from all participants.

\section{Consent for publication}

Not applicable.

\section{Competing interests}

The authors have no competing interests to declare.

\section{Author details}

${ }^{1}$ Family Medicine Department, Prince Sultan Military Medical City (PSMMC), Riyadh, Riyadh, Saudi Arabia. ${ }^{2}$ George Mason University, Fairfax, VA, USA.

Received: 21 May 2020 Accepted: 3 August 2020

Published online: 15 September 2020

\section{References}

1. Al-Nozha MM, Abdullah M, Arafah MR, Khalil MZ, Khan NB, Al-Mazrou YY, et al. Hypertension in Saudi Arabia. Saudi Med J. 2007;28(1):77-84.

2. Chobanian AV, Bakris GL, Black HR, et al. Prevention, detection, evaluation, and treatment of high blood pressure the seventh report of the joint National Committee on complete report. Natl High Blood Press Educ Progr. 2003;42(6):1206

3. De Geest S, Sabaté E. Adherence to long-term therapies: Evidence for action. Eur J Cardiovasc Nurs. 2003;2:323.

4. Bramley TJ, Gerbino PP, Nightengale BS, Frech-Tamas F. Relationship of blood pressure control to adherence with antihypertensive monotherapy in 13 managed care organizations. J Manag Care Pharm. 2006;12(3):239-45.

5. Saeed AA, Al-Hamdan NA, Bahnassy AA, Abdalla AM, MAF A, Abuzaid LZ. Prevalence, awareness, treatment, and control of hypertension among Saudi adult population: A national survey. Int J Hypertens. 2011, 2011:174135 Available from: http://www.ncbi.nlm.nih.gov/pubmed/21912737. [cited 2020 May 4].

6. Elbur Al. Level of adherence to lifestyle changes and medications among male hypertensive patients in two hospitals in taif; kingdom of Saudi Arabia. Int J Pharm Pharm Sci. 2015:7(4):168-72.

7. Ramli A, Ahmad NS, Paraidathathu T. Medication adherence among hypertensive patients of primary health clinics in Malaysia. Patient Prefer Adherence. 2012;6:613-22.

8. Al-Sowielem LS, Elzubier AG. Compliance and knowledge of hypertensive patients attending PHC centres in Al-Khobar, Saudi Arabia. East Mediterr Heal J. 1998:4(2):301-7 Available from: https://apps.who.int/iris/handle/1 0665/118129. [cited 2020 May 4]. 
9. Hadi N, Rostami-Gooran N. Determinant factors of medication compliance in hypertensive patients of Shiraz, Iran. Arch Iran Med. 2004;7(4):292-6 Available from: https://www.sid.ir/en/journal/ViewPaper.aspx? ID=13626. [cited 2020 May 4].

10. Roger VL, Go AS, Lloyd-Jones DM, Benjamin EJ, Berry JD, Borden WB, et al. Heart disease and stroke statistics-2012 update: a report from the American heart association. Circulation. 2012;3:125(1).

11. Goussous LS, Halasah NA, Halasa M. Non - Compliance to Antihypertensive Treatment among Patients Attending Prince Zaid Military Hospital. World Fam Med Journal/Middle East J Fam Med. 2015;13(1):15-9 Available from: https://platform.almanhal.com/Files/2/58839. [cited 2020 May 4].

12. Schoberberger R, Janda M, Pescosta W, Sonneck G. The COMpliance praxiS survey (COMPASS): a multidimensional instrument to monitor compliance for patients on antihypertensive medication. J Hum Hypertens. 2002;16(11) 779-87.

13. Hyre AD, Krousel-Wood MA, Muntner P, Kawasaki L, KB DS. Prevalence and Predictors of Poor Antihypertensive Medication Adherence in an Urban Health Clinic Setting. J Clin Hypertens. 2007;9(3):179-86 Available from: http://doi.wiley.com/10.1111/j.1524-6175.2007.06372.x. [cited 2020 May 4].

14. Issa H, Banna A, Mohmed LH. Compliance and knowledge of hypertensive patients attending Shorsh Hospital in Kirkuk Governorate. Iraqi Postgrad Med J. 2010;9(2):145-50.

15. Klootwyk JM, Sanoski CA. Adherence and persistence in hypertension management. J Clin Outcomes Manag. 2011;18(8):351-8.

16. Karaeren H, Yokuşoǧlu M, Uzun \$̧, Baysan O, Köz C, Kara B, et al. The effect of the content of the knowledge on adherence to medication in hypertensive patients. Anadolu Kardiyol Derg. 2009;9(3):183-8.

17. Ghembaza MA, Senoussaoui Y, Tani M, Meguenni K. Impact of patient knowledge of hypertension complications on adherence to antihypertensive therapy. Curr Hypertens Rev. 2014;10(1):41-8.

18. Elzubier AG, Al-Shahri MA. Drug control of hypertension in primary health care centers-registered patients, Al-khobar, saudi arabia. J Family Community Med. 1997;4(2):47-53 Available from: http://www.ncbi.nlm.nih. gov/pubmed/23008573. [cited 2020 May 4].

19. Morisky DE, Ang A, Krousel-Wood M, Ward HJ. Predictive validity of a medication adherence measure in an outpatient setting. J Clin Hypertens. 2008;10(5):348-54.

20. González-fernández RA, Rivera M, Torres D, Quiles J, Jackson A. Usefulness of a systemic hypertension in-hospital educational program. Am J Cardiol. 1990;65(20):1384-6.

21. Brown J, Mellott S. The healthcare quality handbook : a professional resource and study guide; 2016. p. 439.

22. Mafutha GN, Wright SCD. Compliance or non-compliance of hypertensive adults to hypertension management at three primary healthcare day clinics in Tshwane. Curationis. 2013;36(1):E1-6.

23. Hussanin S, Boonshuyar C, Ekram A. Non-adherence to antihypertensive treatment in essential hypertensive patients in Rajshahi, Bangladesh. Anwer Khan Mod Med Coll J. 2011;2(1):9-14.

24. Al-Mehza AM, Al-Muhailije FA, Khalfan MM, Al-Yahya AA. Drug compliance among hypertensive patients; an area based study. Eur J Gen Med. 2009; 6(1):6-10 Available from: http://www.ejgm.co.uk/download/drugcompliance-among-hypertensive-patients-an-area-based-study-6685.pdf. [cited 2020 May 4].

25. Busari OA, Olanrewaju TO, Desalu OO, Opadijo OG, Jimoh AK, Agboola SM, et al. Impact of Patients' Knowledge, Attitude and Practices on Hypertension on Compliance with Antihypertensive Drugs in a Resourcepoor Setting. TAF Prev Med Bull. 2010;9(2):87-92 Available from: www. korhek.org. [cited 2020 May 4].

26. Fitz-Simon N, Bennett K, Feely J. A review of studies of adherence with antihypertensive drugs using prescription databases. Ther Clin Risk Manag. 2005;1(2):93-106

27. Lee GKY, Wang HHX, Liu KQL, Cheung Y, Morisky DE, Wong MCS Determinants of medication adherence to antihypertensive medications among a Chinese population using Morisky medication adherence scale. PLoS One. 2013;8(4):e62775.

28. Gonzalez J, Williams JW, Noël PH, Lee S. Adherence to mental health treatment in a primary care clinic. J Am Board Fam Pract. 2005;18(2):87-96.

29. Ambaw AD, Alemie GA, Wyohannes SM, Mengesha ZB. Adherence to antihypertensive treatment and associated factors among patients on follow up at University of Gondar Hospital, Northwest Ethiopia. BMC Public Health. 2012;12(1):282.
30. Syed ST, Gerber BS, Sharp LK. Traveling towards disease: transportation barriers to health care access [internet]. J Commun Health. 2013;38:976-93 Available from: http://www.ncbi.nlm.nih.gov/pubmed/23543372. [cited 2020 May 4].

31. Saudi Hypertension Management Society. Saudi Hypertension Guidelines. 2018.

32. Marcum ZA, Gellad WF. Medication Adherence to Multidrug Regimens. Clin Geriatr Med. 2012;28(2):287-300 Available from: http://www.ncbi.nlm.nih. gov/pubmed/22500544. [cited 2020 May 5].

33. Neutel JM, Smith DHG. Improving Patient Compliance: A Major Goal in the Management of Hypertension. J Clin Hypertens. 2003;5(2):127-32 Available from: http//doi.wiley.com/10.1111/j.1524-6175.2003.00495x. [cited 2020 May 5].

\section{Publisher's Note}

Springer Nature remains neutral with regard to jurisdictional claims in published maps and institutional affiliations.
Ready to submit your research? Choose BMC and benefit from:

- fast, convenient online submission

- thorough peer review by experienced researchers in your field

- rapid publication on acceptance

- support for research data, including large and complex data types

- gold Open Access which fosters wider collaboration and increased citations

- maximum visibility for your research: over $100 \mathrm{M}$ website views per year

At BMC, research is always in progress.

Learn more biomedcentral.com/submissions 